\title{
EFFECT OF SINGLE AND DUAL INOCULATION WITH Rhizobium leguminosarum BV. TRIFIOLII AND Anabaena SP. ON SEEDLING RICE GROWTH UNDER LABORATORY CONDITIONS \\ Hauka, F. I. A. ${ }^{1}$; Aida H. A. Amer ${ }^{1}$;M. M. El-Sawah'; ;Y. G. Yanni' ${ }^{2}$ and A. Youssef Elsaadany ${ }^{1}$ \\ ${ }^{1}$ Dept. of Microbiology, Fac. of Agric., Mans. Univ., ${ }^{2}$ Sakha Agric. Research Station, Kafr El-Sheikh
}

\begin{abstract}
Plant growth promoting activities for the local isolated and identified rhizobial and cyanobacterial strains were performed under gnotobiotic conditions in laboratory. The experiment contained four Egyptian rice varieties (Sakha 101, Sakha 104, Giza 177 and Giza 178) that were tested against the Rhizobium leguminosarum (RH) strain $\mathrm{E} 11$ and the Anabaena sp. strain ERC102 and their consortia. The results indicate that inoculation with the $\mathrm{RH}$ E11 alone stimulated root and shoot growth of the three rice varieties Sakha 101, Sakha 104 and Giza 178. The plant growth promotion provided by inoculation with Rlt E11 alone was better than for inoculation with the cyanobacterial strain alone or when the strains were mixed in a consortia inoculum.
\end{abstract}

\section{INTRODUCTION}

Numerous species of soil bacteria that flourish in plant rhizosphere may grow in, on, or around plant tissues, stimulate plant growth by a plethora of mechanisms. These bacteria are collectively known as PGPR (Plant Growth Promoting Rhizobacteria). The search for PGPR and investigation of their modes of action are increasing at a rapid pace as efforts are made to exploit them commercially as biofertilizers which must be tested for their efficiencies in establishment of effective plant microbe interrelationships that can benefit plant growth and crop performances while do not have pathogenic effects to plants, humans, animals or adverse impact on the environment. Inoculation with those microorganisms, when tested and found effective, can assist plant growth stimulation by providing fixed nitrogen or secretion of growth hormones that induce better plant growth, nutrient uptake and increased tolerance towards drought and/or salinity stress. The cost/benefit ratio of biofertilizers is always higher. Costs of fertilization with nitrogen and phosphorous chemical fertilizers is so commonly an economic limiting factor in crop production in most of the world, which can be mitigated by biofertilization (Anandaraj and Delapierre, 2010). Cyanobacterial strains belonging to Nostoc and Anabaena comprised $80 \%$ of the rhizosphere isolates of cyanobacteria, which were found efficient in enhancing germination and growth of rice seeds and exhibited significantly high protein accumulation, IAA production and nitrogen fixation (Prasanna et al., 2009).

Endophytic bacteria, as defined by (Hallmann et al., 1997), are bacteria that can be isolated from inside surface-disinfested plant tissue and do not visibly harm the plant. It is a practical definition based on experimental limitations and is inclusive of bacterial symbionts, as well as internal plant- 
Hauka, F. I. A. et al.

colonizing nonpathogenic bacteria with unknown beneficial or detrimental effects on colonized plants. Historically, endophytic bacteria have been considered weakly virulent plant pathogens. Recently, been discovered to have several beneficial effects on host plants, containing plant growth promotion and increased resistance against plant pathogens and parasites.

The strategy followed to achieve this goal consisted of two consecutive steps that can be summarized in:

1-Isolation, purification and identification of strain belonging to $\mathrm{N}$-fixing cyanobacteria from rice fields and Rhizobium leguminosarum biovar trifoli that already tested and found successful for rice biofertilization in the Nile delta (Yanni and Dazzo 2010).

2-Testing the performance of these bacteria, individually and when used as consortia, in enhancement of rice seedling growth under gnotobiotic lab culture conditions.

\section{MATERIALS AND METHODS}

\section{Isolation of clover-nodulating Rhizobium from roots of field-grown rice}

Rhizosphere soil and roots of the Japonica rice cultivar Giza-172 were collected from fields at Sakha, Kafr El- Sheikh Governorate, where rice has been rotated with Egyptian berseem clover for several hundred years. The roots were washed with running tap water followed by distilled water, surface-sterilized with $70 \%$ ethanol followed by $10 \%$ sodium hypochlorite, rolled over Yeast Extract Mannitol (YEM) gar plates to verify root surfacesterilization, and macerated in sterile $5 \mathrm{mM}$ Na-phosphate buffer of $\mathrm{pH} 7.0$. Authentication followed by enumeration of Rhizobium. in the surface-sterilized I macerated rice roots was performed by the five-tube most probable number (MPN) - plant infection test (Somasegaran and Hoben, 1985) using berseem clover (Trifolium alexandrinum) as the legume trap host. Tubes containing Vincent's nitrogen-free agar medium were planted with surface-sterilized clover seeds and left for germination for 3 days before inoculation with the preprepared rice root macerate. The seedlings were incubated under $16 \mathrm{hr}$ day light, $70 \%$ relative humidity, and $22{ }^{\circ} \mathrm{C}$ day $/ 20^{\circ} \mathrm{C}$ night cycle for 32 days in lab green house and then scored for root nodulation. Root nodules that developed on clover plants inoculated with the highest dilutions of rice root macerates were excised, surface-sterilized, and the nodule occupants were isolated into pure culture by plating on YEM agar followed by restreaking of the isolated colonies on defined BIII agar medium (Dazzo, 1982).

Analyses of the symbiotic properties of the selected isolates in pure culture were performed on Egyptian berseem clover seedlings (8 replicates per treatment) grown on agar slopes of $\mathrm{N}$-free Fahraeus medium under microbiologically controlled conditions (Dazzo, 1982). Seedling roots were inoculated with $10^{6}$ cells of a 5 -day-old inoculum and incubated in growth chamber under the same conditions described above. Nodulation kinetics was assessed by periodically inspecting plants using stereomicroscopy for emergence of root nodules. The plants were harvested at 41 days after 
inoculation and evaluated for effectiveness in symbiotic $\mathrm{N}$ fixation by comparison of their dry weight and $\mathrm{N}$-content (estimated by the microKjeldahl steam distillation method, Black et al., 1965) to that of the noninoculated control plants.

Analysis of rhizobial strain diversity and identification of endophytic isolates by molecular methods

Plasmid profiles were analyzed by the method of (Eckhardt, 1978) as modified by (Espuny et al., 1987). Genomic Restriction Fragment Length Polymorphism (RFLP) of Xba1 digests was analyzed by pulsed- field gel electrophoresis as described by (Corich et al., 1991). BOX-PCR amplification fragment length polymorphism was analyzed as described by (Versalovic et al., 1994). Cells were also boiled in SDS gel buffer (Laemmli, 1970 ) and the profiles of their total cellular proteins were compared by SDSPAGE in $12 \%$ running gels stained with Coomassie blue. The phylogenetic relationships of the $R$. leguminosarum bv. trifolii strains (given the names E11 $E=$ =Egypt) were analyzed by sequencing their total 16S rDNA. The 16S ribosomal RNA-encoding genes were amplified from genomic DNA using conserved eubac-terial primers $8 \mathrm{~F}$ and $1540 \mathrm{R}$. The amplified product was sequenced using dye terminators on the Applied Biosystems' DNA Sequencing System (Foster City, CA). Sequences were aligned against those in the Ribosomal Database Project (Larsen et al., 1993) on the basis of conserved regions of sequence and secondary structure. Phylogenetic relationships were inferred using regions of unambiguous alignment and the distance method of ( DeSoete, 1984).

Microscopical examination of Rhizobium endophytes within rice roots

Rice seedlings were grown for 32 days in non-sterile potted soil in a growth chamber as previously described (de Bruijn et al., 1995). Roots were sampled, cleaned with running water, freehand sectioned, and processed for examination by scanning electron microscopy (Umali-Garcia et al., 1980). Other seedlings were grown under microbiologically controlled conditions in enclosed tubes inoculated with pure cultures of the rice endophyte $\mathrm{RH}$ strain E11. Freehand sections were stained with $0.01 \%$ acridine orange, washed and mounted in $1 \%$ sodium pyrophosphate, and examined by laser scanning microscopy in the epifluorescence confocal mode using computer-enhanced reconstruction of serial section overlays and digital image processing (Subba-Rao et al., 1995).

Isolation and identification of Anabaena spp.

Field grown rice plants were carefully uprooted and transferred to the "Blue-green Algae Research lab at Sakha Agricultural research Station, Kafr ElSheikh". The roots were washed several times with running distilled water to remove mud and soil particles. The major roots were excised, surface sterilized with $70 \%$ ethanol followed by $1 \%$ sodium hypochlorite solution, cut into pieces under sterile conditions, and then macerated in sterile $5 \mathrm{~m} \mathrm{M} \mathrm{Na-phosphate}$ buffer $(\mathrm{pH} 7)$. Sterile dilutions from $10^{-1}$ to $10^{-8}$ of the sterile rice root macerates. The dilutions containing the root macerates were used for inoculation of $\mathrm{N}$-free mineral plant nutrient medium (The Modified Watanabe medium, El - Nawawy et al. 1958), with incubation under photosynthetic illumination of 14 light and 10 dark for 10 days under temperatures of 24 to $30{ }^{\circ} \mathrm{C}$ for isolation of the 
Hauka, F. I. A. et al.

cyanobacterium. Standard microbiological methods were used to establish pure cultures of the isolated organisms and maintain their viability in culture collections. Grouping of the isolates into genomically distinct strains was done by plasmid profiling and BOX-PCR genomic fingerprinting techniques. Confirmation of their taxonomic status is made by the aforementioned bioinformatic comparison of their 16S rRNA sequences to appropriate databases.

\section{Growth of rice under gnotobiotic conditions}

Laboratory studies of the interaction between rice and clovernodulating rhizobial endophytes were performed using an enclosed sterile tube culture system under climate-controlled growth chamber conditions. The rice varieties Sakha 101, Sakha 104, Giza 177 and Giza 178 were used for this study. The Rhizobium leguminosarum bv. trifolii strain E11 was used among Separate tests established that seeds of the four rice cultivars harbored no endophytic clover-nodulating rhizobia that would survive surfacesterilization. Seeds weighing approximately $30 \mathrm{mg}$ each were surfacesterilized by treatment with $70 \%$ ethanol for 1 min followed by $10 \%$ sodium hypochlorite solution for $4 \mathrm{~min}$, and then washed (four times one min each) with sterile water, then transferred to twenty-five $200 \mathrm{~mm}$ tubes, each enclosed with foam plugs and containing $20 \mathrm{ml}$ of Hoagland's plant growth medium (Sigma Chem. Co., St. Louis, MO) solidified with $1 \%$ purified agar (United States Biochemical, Cleve- land, $\mathrm{OH}$ ), above which was layered $5 \mathrm{~g}$ of sterile acid-washed quartz sand and $4 \mathrm{~mL}$ sterile Hoagland's \#2 liquid medium. The tubes were incubated for 2 days in the dark at $30{ }^{\circ} \mathrm{C}$ for seed germination. Rhizobial inoculum was grown separately on BIII agar for 5 days at $30 \mathrm{oC}$, suspended in sterile Hoagland's medium and adjusted to a density of 107 cells $\mathrm{mL}-1$. The cyanobacterial inoculate was grown on $\mathrm{N}$-free medium for 5 days under illumination program of $14 \mathrm{hrs} \mathrm{light} \mathrm{/} 10 \mathrm{hrs}$ dark in the lab growth chamber maintained at $31+0.5{ }^{\circ} \mathrm{C}$. Each seedling root was inoculated with $106 \mathrm{CFU}$ of each of the two organisms or them both as a consortium, and tested against a non-inoculated control treatment. Six plant replicates were used for each treatment). When grown to sufficient length, the stem was repositioned through a slit on the edge of the foam plug to allow continuous growth while preventing microbial contamination of the root system. Tubes were irrigated with sterile water alternating with equal quantities of sterile Hoagland's solution as needed. Rice plants in tube culture were gently uprooted 32 days after inoculation and excised at the stem base. Root biovolume and shoot height, are tabulated later in the results section.

\section{Screening of plant growth-promotion activities}

Bioassays were performed using different varieties of rice seedlings maintained under microbiologically controlled, gnotobiotic growth conditions in plant growth chambers. A variety of microscopy methods are employed to study their colonization of rice roots, including immunofluorescence microscopy, confocal laser-scanning microscopy and scanning electron microscopy. Quantization of their colonization patterns is done by computerassisted microscopy and digital image analysis using the 
software CMEIAS [Center of Microbial Ecology Image Analysis System (http://cme.msu.edu/cmeias/)].

\section{RESULTS AND DISCUSSION}

\section{Authenticity of the tested bacterial strains}

Isolates of cyanobacteria and rhizobia isolated from surface-sterilized rice roots grown in the Nile delta were examined for authenticity using répétitive extragenomic palindromic-PCR fingerprinting and/or PCRrestriction fragment length polymorphism (RFLP) of 16S-ribosomal (cultivars Giza 177 and Sakha 102). Fig. (1A and B) showing electron micrographes of the epidermal root surface of rice (Sakha 102) colonized by the rice endophyte Rhizobium leguminosarum bv. trifolii (Strain E11).

DNA as intergenic spacers and PCR-RFLP of a nodulation gene region, nodD, as a marker of the symbiotic component of the genome. A $16 \mathrm{~S}$ rDNA sequence analysis for cyanobacterial isolate revealed that its nucleotide sequences are most closely matching the order Nostocales, genus Anabaena. The strain was tested for atmospheric $\mathrm{N}$-fixation and found positive regarding its ability to grow on $\mathrm{N}$-free medium. Phase-contrast and fluorescence photomicrographs are shown below in Fig. $2 \mathrm{~A}, \mathrm{~B}, \mathrm{C}, \mathrm{D}$ and $\mathrm{E}$ and Fig. 3. Red and blue arrows indicate examples of differentiated $\mathrm{N}_{2}$-fixing heterocysts in the filaments.

\section{Promotion of rice growth}

Results of the plant growth promotion test for the rhizobial and cyanobacterial strains (appearing in Figs 1,2 and 3) performed under gnotobiotic controlled condition in a growth chambers (Fig 4) are reported in Table (1). The experiment contained four Egyptian rice varieties tested against the Rhizobium leguminosarum bv. trifiolii (Rt) strain $\mathrm{E} 11$ and the Anabaena sp. strain ERC102 and their consortia. Root biovolume and shoot length were taken as index for the plant growth promotion activity of the tested strains. 
Hauka, F. I. A. et al.
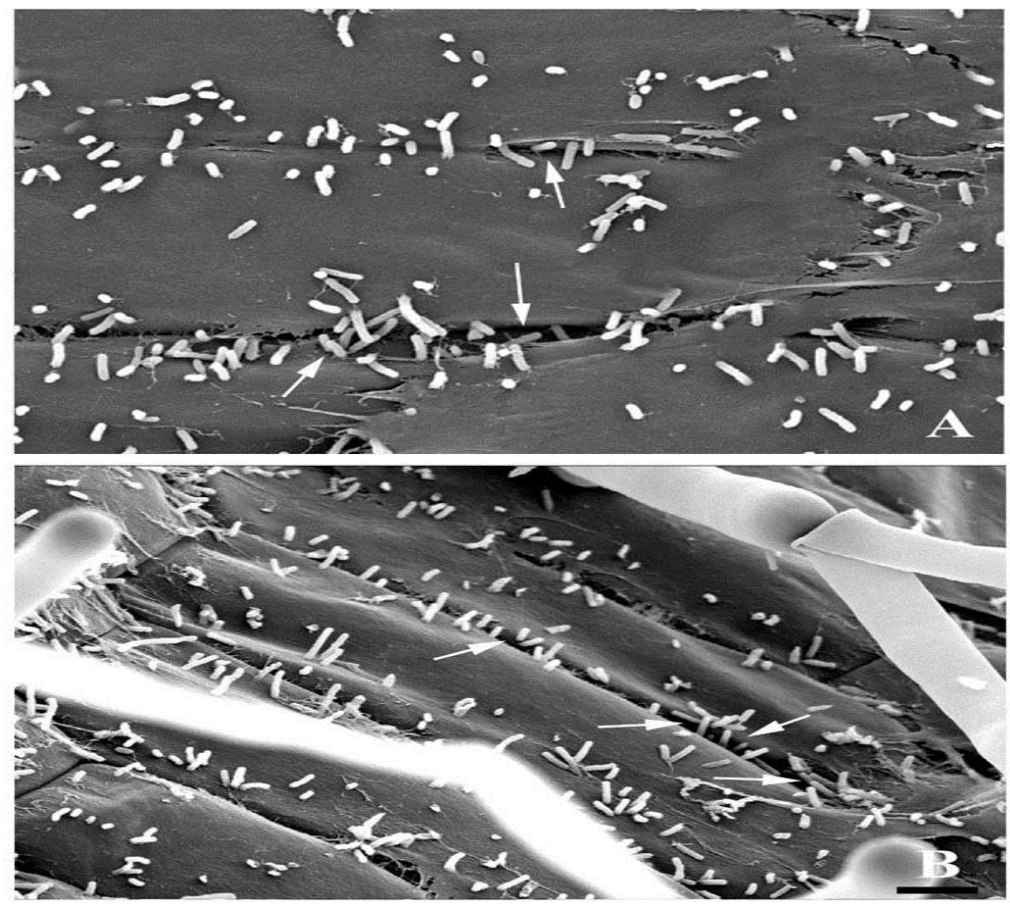

Fig. $1 \mathrm{~A}$ and B: Scanning electron micrographs of the rice Sakha 102 epidermal root surface colonized by an endophyte strain of rice-adapted Rhizobium leguminosarum bv. trifolii (Strain E11).

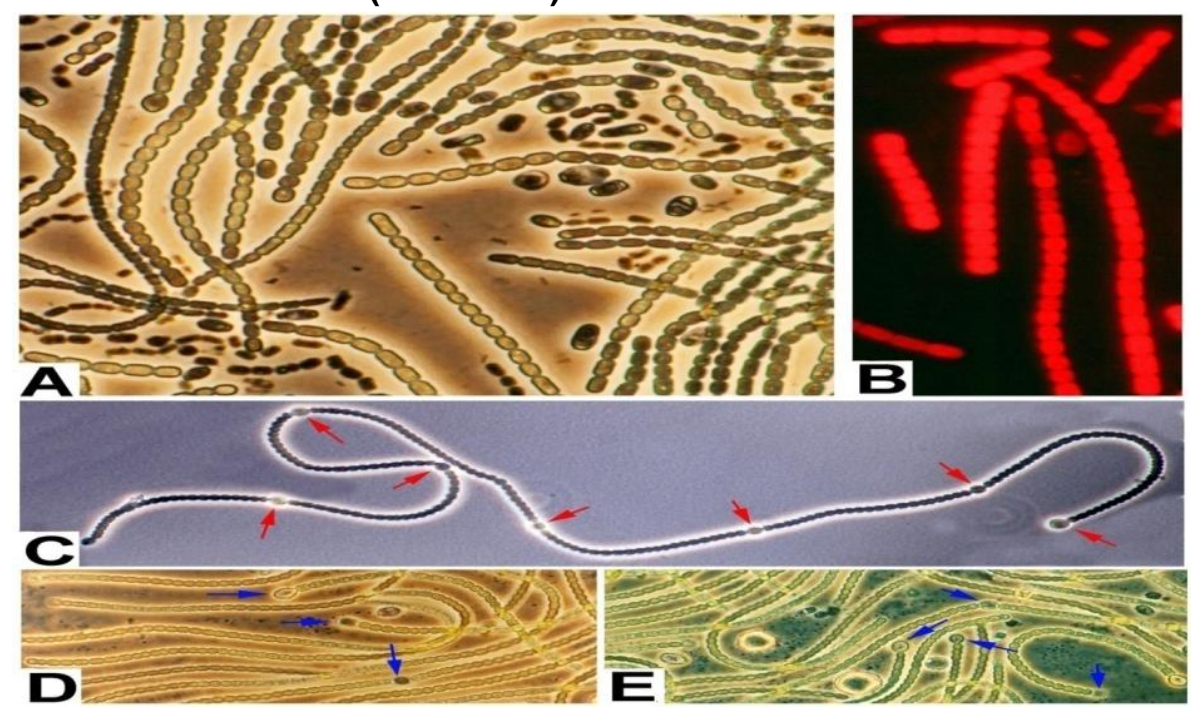

Fig. 2. A and B: Photomicrographs of the cyanobacterial isolates for this study. Arrows in C, D and E point to cells of differentiat heterocysts. 


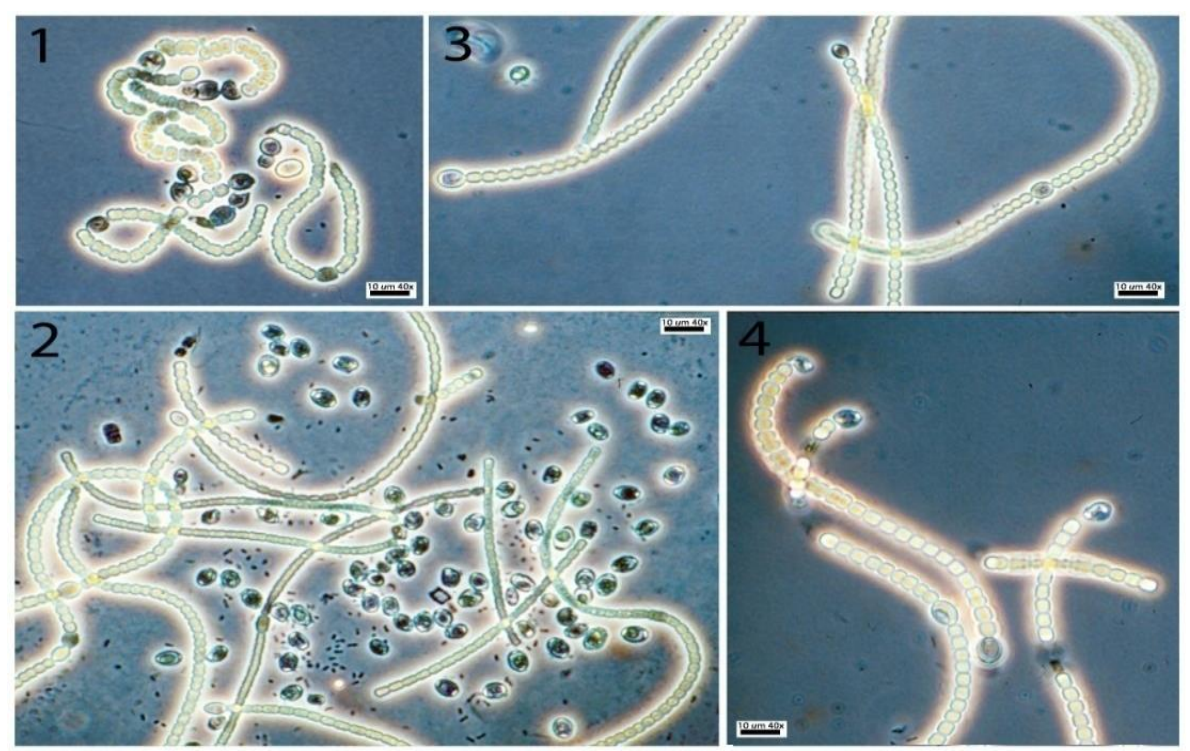

Fig. (3): Filamentous heterocyst-forming cyanobacteria isolated for this study.

The results indicate that inoculation with the $\mathrm{RH}$ E11 alone stimulated root and shoot growth of the three rice varieties Sakha 101, Sakha 104 and Giza 178. The plant growth promotion provided by inoculation with RH E11 alone was better than for inoculation with the cyanobacterial strain alone or when the strains were mixed in a consortia inoculum.

Table1: Effect of inoculation with $R H$ strain E11 and Anabaena sp. strain ERC102 on root biovolume and shoot height of four rice varieties.

\begin{tabular}{|c|c|c|c|}
\hline Rice variety & Bacterial inoculum & Root biovolume $\left(\mathrm{mm}^{\mathrm{T}}\right)$ & Shoot height(mm) \\
\hline \multirow{4}{*}{ Sakha 101} & None & $600 \pm 231$ & $280 \pm 15$ \\
\hline & E11 & $1100 \pm 141$ & $284 \pm 0$ \\
\hline & ERC102 & $575 \pm 50$ & $259 \pm 12$ \\
\hline & $\mathrm{E} 11+\mathrm{ERC} 102$ & $640 \pm 55$ & $275 \pm 13$ \\
\hline \multirow{4}{*}{ Sakha 104} & None & $650 \pm 129$ & $311 \pm 12$ \\
\hline & E11 & $1020 \pm 110$ & $300 \pm 8$ \\
\hline & ERC102 & $820 \pm 45$ & $284 \pm 2$ \\
\hline & $E 11+E R C 102$ & $820 \pm 84$ & $286 \pm 8$ \\
\hline \multirow{4}{*}{ Giza 177} & None & $1067 \pm 115$ & $295 \pm 14$ \\
\hline & E11 & $1000 \pm 82$ & $283 \pm 14$ \\
\hline & ERC102 & $450 \pm 129$ & $271 \pm 19$ \\
\hline & $E 11+E R C 102$ & $875 \pm 150$ & $300 \pm 15$ \\
\hline \multirow[t]{4}{*}{ Giza 178} & None & $325 \pm 50$ & $250 \pm 23$ \\
\hline & E11 & $550 \pm 100$ & $550 \pm 274$ \\
\hline & ERC102 & $300 \pm 0$ & $300 \pm 219$ \\
\hline & $\mathrm{E} 11+\mathrm{ERC} 102$ & $400 \pm 71$ & $400 \pm 222$ \\
\hline
\end{tabular}

The Table reports the means +/- standard deviation for the root biovolume $\left(\mathrm{mm}^{3}\right)$ and shoot length $(\mathrm{mm})$ for the four rice varieties vs. three inoculation treatments 
Hauka, F. I. A. et al.

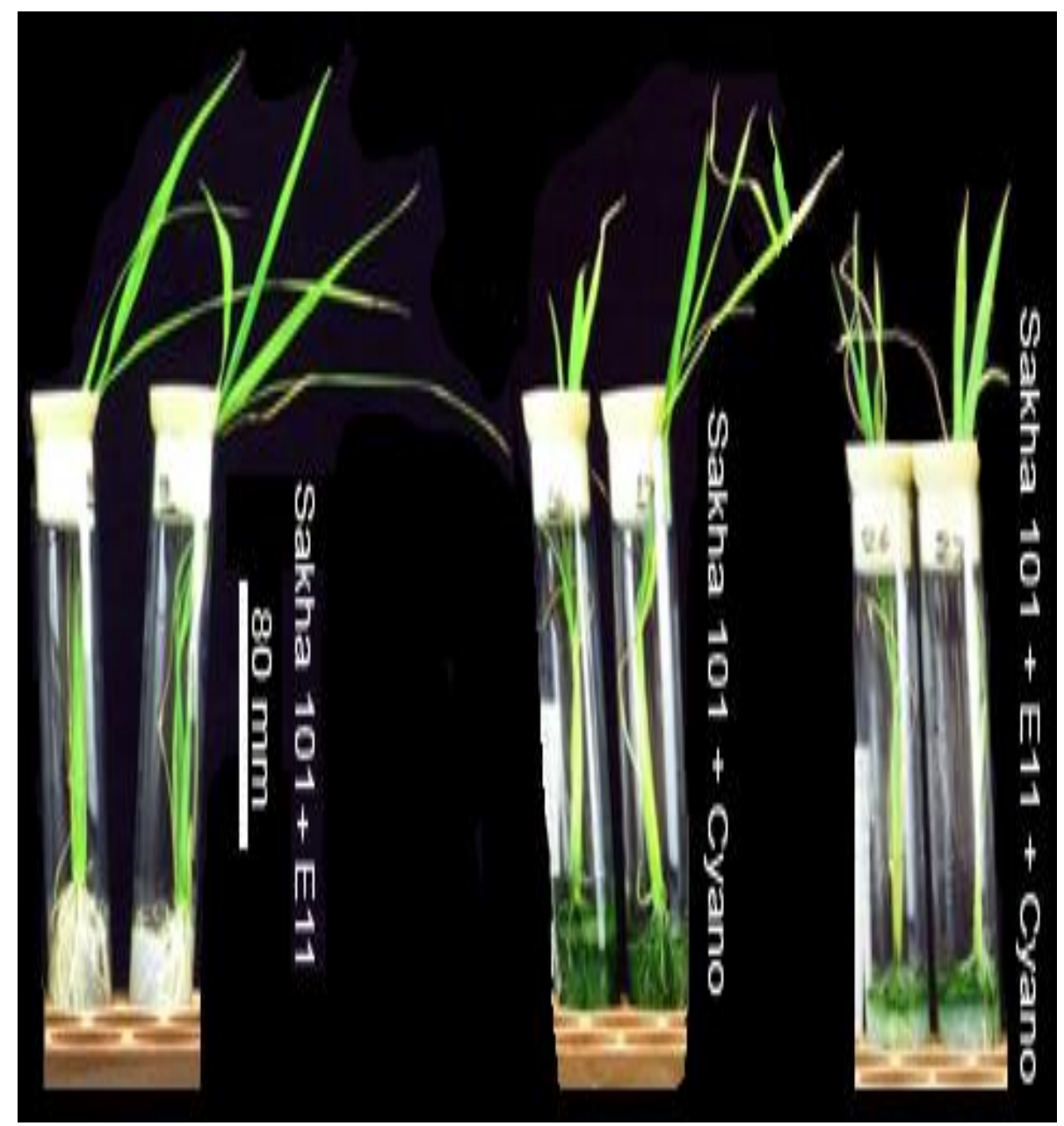

Fig.4: Gnotobiotic tube cultures showing the growth response of Sakha 101 rice to inoculation with $R$. leguminosarum bv. trifolii E11, with a cyanobacterial isolate, and with a consortium containing rhizobial strain E11 plus the same cyanobacterial isolate. (Note stunted vegetative growth of plants inoculated with the cyanobacterial isolate).

Results of the gnotobiotic experiment performed in glass tube culture using $50 \%$ Hoagland \#2 (the composite Fig 4, supported by Table 1) showed that that in the closed habitat of the culture glass tube, the inoculated cyanobacteria competed with the plant for available macro- and micronutrients necessary for growth of both of them. The endophytic rhizobia, in turn, assisted the plant to absorb more nutrients due to mechanisms involving enhanced root architecture (increased biovolume, cumulative length and surface area as described in: Yanni et al., 1997, Biswas et al. 
,2000a,b; Chaintreuil et al., 2000, Yanni et al., 2001, Ladha and Reddy, 2003 and Chi et al., 2005). The plant and the cyanobacterium then competed in the gnotobiotic habitat against each other for the nutrients provided by the growth medium. Although the cyanobacteria is an active $\mathrm{N}$-fixer, the inoculated plants seems faint, weak and suffering a sort of growth retardation than those which were inoculated by t Rhizobium. However, rice plant growth in open fields do not suffer consequences of such competition as supply of micronutrients from different sources, importantly soil, flood and irrigation water, decay of plant residues, small animals, macro and microorganisms etc., normally secure continues supply of micronutrients all over the plant growth period. Supply with phosphorus may be an exception as the element accumulates in the algal and cyanobacterial cells during the early stages of plant growth, during which sunlight incidence is high and proliferation of algal and cyanobacterial blooms is at its maximum. Later on, phosphorus, nitrogen and other macro and micronutrients liberate during the later rice growth stages when the algal blooms start to decay because of the increased rice plant canopy that prevent sunlight needed for continuity of algal photosynthesis.. This mechanism is very beneficial to the crop, as this phosphorus liberation is highly needed during the panicle initiation stage. Data presented by (Subrahmanyan et al., 1965), (Arora, 1969) and (Roger and Kulasooriya, 1980), and references herewith explained and discussed this mechanism in rice fields. However, seems that the short duration of the gnotobiotic bioassay experiment was only enough for nutrient absorption by the cyanobacterial cells that competed with the plant on available nutrients. However, the results indicate clear difference between nutrient competition between the plant and cyanobacteria on one hand versus the enhancement relationship between the rhizobia and the plant with enhanced nutrients uptake is evident!

When $\mathrm{N}$-fixing cyanobacteria are to be used in rice biofertilization, it is necessary to apply a starter chemical $\mathrm{N}$-fertilizer dose of around $1 / 4$ to $1 / 3$ of its $\mathrm{N}$-demand to help the plant to grow well during the early period in which the cyanobacterial population establishes well in the field and starts to fix adequate amounts of atmospheric- $\mathrm{N}_{2}$, followed by decomposition/mineralization of the cyanobacteria after the rice canopy develops, liberating both the biologically fixed- $\mathrm{N}$ and the other macro- and micro-nutrients consumed by the cyanobacteria during their early stages of growth. Only then will those fixed- $\mathrm{N}$ and nutrients become available to the rice plant.

\section{REFERENCES}

Anandaraj, B. and Delapierre, L. R. (2010). Studies on influence of bioinoculants (Pseudomonas fluorescens, Rhizobium sp., Bacillus megaterium) in Green gram. Journal of Bioscience and Technology, 1(2): 95-99.

Arora, S. (1969). The role of algae in the availability of phosphorus in paddy fields. Riso, 18:135-138. 
Hauka, F. I. A. et al.

Biswas, J. C.; Ladha, J. K. and Dazzo, F. B. (2000a). Rhizobia inoculation improves nutrient uptake and growth of lowland rice. Soil Science Society American Journal, 64: 1644-1650.

Biswas, J. C.; Ladha, J. K.; Dazzo, F. B.; Yanni, Y. G., and Rolfe, B. G. (2000b). Rhizobial inoculation influences seedling vigor and yield of rice. Agronomy Journal, 92: 880-886.

Black, A.; Evans, D. D.; Ensmingers, L. E.; White, J. L. andClark, F. E. (1965). Methods of Soil Analysis. Part2 Chemical and microbiological properties. No.9, Series of Agronomy, American Society of Agronomy Inc., Madison, Wisconsin, USA.

Chaintreuil, C.; Giraud, E.; Prin, Y.; Lorquin, J., Ba, A.; Gillis, M.; de Laudie, P. and Dreyfus, B. (2000). Photosynthetic bradyrhizobia are natural endophytes of the African wild rice Oryza breviligulata. Appl Environ Microbiol 66:5437-5447.

Chi, F.; Shen, S.; Cheng, H.; Jing. Y.; Yanni, Y. G. and Dazzo, F. B. (2005). Ascending migration of endophytic Rhizobia, from roots to leaves, inside rice plants and assessment of benefits to rice growth physiology. Applied and Environmental Microbiology, 71(11): 7271-7278.

Corich, V.; Giacomini, A.; Ollero, F. J.; Squartini, A. and Nuti, M. P. (1991). Pulsed-field electrophoresis in contour-clamped homogeneous electric fields (CHEF) for the fingerprinting of Rhizobium spp. FEMS Microbiol. Lett. 83, 193-198.

Dazzo, F. B. (1982). Leguminous root nodules. In "Experimental Microbial Ecology". (Eds. R. Burns and J. Slater) pp. 431-446. (Blackwell Scientific Press, Cambridge).

de Bruijn, F. J.; Jing, Y. and Dazzo, F. B. (1995). Potentials and pitfalls of trying to extend symbiotic interactions of nitrogen-fixing organisms to presently non-nodulated plants, such as rice. Plant and Soil 174, 225240.

DeSoete, G. (1984). Additive-tree representations of incomplete dissimilarity data. Quality and Quantity 18, 387-393.

Eckhardt, T. (1978). A rapid method for the identification of plasmid deoxyribonucleic acid in bacteria. Plasmid 1, 584-588.

El- Nawawy, A.S.; Lotfi, M. and Fahmy, M. (1958). Studies on the ability of some blue- green algae to fix atmospheric nitrogen and their effect on growth and yield of paddy. Agric. Res. Rev., Min. of Agric., Cairo, 36:308-320.

Espuny, M. R.; Ollero, F. J.; Bellogin, R. A.; Ruiz-Sainz, J. E. and PerezSilva, J. (1987). Transfer of the Rhizobium leguminosarum biovar trifolii symbiotic plasmid pRtr5a to a strain of Rhizobium sp. that nodulates Hedysarum coronarium. J. Appl. Bacteriol. 63, 13-20.

Hallmann, J.; Mahaffee, W. F., Kloepper, J. W. and Quadt-Hallmann, A. (1997). Bacterial endophytes in agricultural crops. Canadian Journal of Microbiology, 43(10): 895-914.

Ladha, J. K. and Reddy, P. M. (2003). Nitrogen fixation in rice systems: state of knowledge and future prospects. Plant and Soil, 252: 151-167.

Laemmli, U. (1970). Cleavage of structural proteins during the assembly of the head of bacteriophage T4. Nature (London) 227: 680-685 
Larsen, N.; Olsen, G.; Maidak, B.; McCaughey, M.; Overbeek, R.; Macke, T.; Marsch, T. and Woese, C. R. (1993). The ribosomal database project. Nucl. Acid Res. 21, 3021-3032.

Prasanna, R.; Jaiswal, P.; Nayak, S.; Sood, A. and Kaushik, B. D. (2009). Cyanobacterial diversity in the rhizosphere of rice and its ecological significance. Indian Journal of Microbiology, 49(1): 89-97.

Roger, P. A. and Kulasooriya, S. A. (1980). Blue-green algae and rice. international Rice Research Institute, Los Banos, Philippines.

Somasegaran, P. and Hoben, H. J. (1985). Methods in Legume-Rhizobium Technology". University of Hawaii NifTAL Project and MIRCEN, Dept. of Agronomy and Soil Science. Hawaii Institute of Tropical Agriculture and Human Resources, College of Tropical Agriculture and Human Resources, Hawaii.

Subba-Rao, N. S.; Mateos, P. F.; Baker, D.; Pankratz, H. S.; Palma, J.; Dazzo, F. B. and Sprent, J. I. (1995). The unique root-nodule symbiosis between Rhizobium and the aquatic legume, Neptunia natans (L. f.) Druce. Planta 196, 311-320.

Subrahmanyan, R.; Relwani, L. L. and Manna, G. B. (1965). Fertility build-up of rice field soils by blue-green algae. Proc Indian Acad Sci Series B 62:252-277.

Umali-Garcia, M.; Hubbell, D. H.; Gaskins, M. H. and Dazzo, F. B. (1980). Association of Azospirillum with grass roots. Appl. Environ. Microbiol. 39, 219-226.

Versalovic, J.; Schneider, M.; de Bruijn, F. J. and Lupski, J. R. (1994). Genomic fingerprinting of bacteria using repetitive sequence-based polymerase chain reaction. Methods in Molecular and Cellular Biology. 5, 25-40.

Yanni, Y. G. and Dazzo, F. B. (2010). Enhancement of rice production using endophytic strains of Rhizobium leguminosarum bv. trifolii in extensive field inoculation trials within the Egypt Nile delta. Plant and Soil, 336:129-142.

Yanni, Y. G.; Rizk, R. Y.; Abd El-Fattah, F.; Squartini, A.; Corich, V.; Giacomini, A.; de Bruijn, F.; Rademaker, J.; Maya-Flores, J.; Ostrom, P.; Vega-Hernandez, M.; Hollingsworth, R. I.; Martinez-Molina, E.; Mateos, P.; Velazquez, E.; Wopereis, J.; Triplett, E.; Umali-Garcia, M.; Anarna, J. A.; Rolfe, B. G.; Ladha, J. K.; Hill, J.; Mujoo, R.; Ng, P. K. and Dazzo, F. B. (2001). The beneficial plant growth-promoting association of Rhizobium leguminosarum bv. trifolii with rice roots. Austr J Plant Physiol 62:845-870.

Yanni, Y. G.; Rizk, R. Y.; Corich, V., Squartini, A.; Ninke, K.; PhilipHollingsworth, S.; Orgambide, G., de Bruijn, F.; Stoltzfus, J.; Buckley, D.; Schmidt, T. M.; Mateos, P. F.; Ladha, J. K. and Dazzo, F. B. (1997). Natural endophytic association between Rhizobium leguminosarum bv. trifolii and rice and assessment of its potential to promote rice growth. Plant and Soil, 194: 99-114. 
Hauka, F. I. A. et al.

Rhizobium leguminosarum تأثير التلقيح الفردى و المزدوج بكل من على نمو بادرات الأرز تحت الظروف Rv. trifiolii and Anabaena sp المعملية

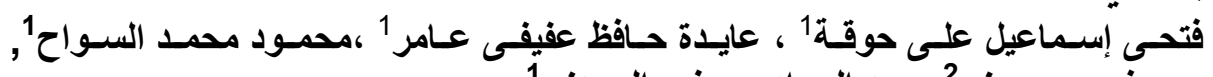

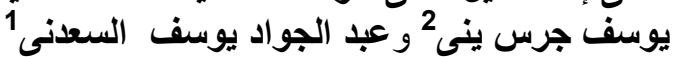

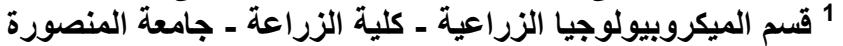
20 محطة البحوث الزراعية بسخا - كفر الثيخ

أجريت هذه الدراسة للحصول على عزلة الريزوبيم من داخل الجذور المعقمة لنبات الأرز النامي في مناطق بشمال

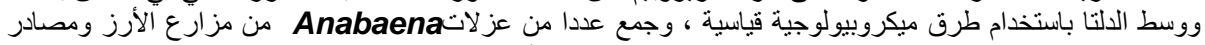

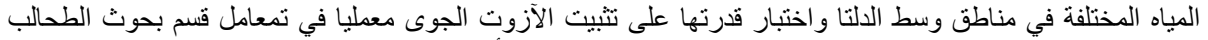

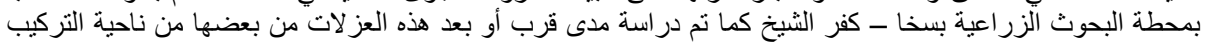

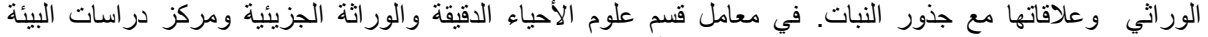

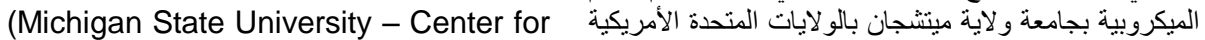
Microbial Ecology, USA

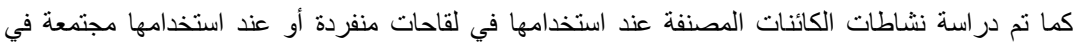

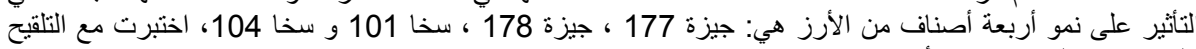

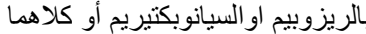

أظهرت نتائج تصنيف العزئلات كونها تنتمي إلى الأجناس والأنواع الآتية: (وأعطى اسما لكل منها كما هو موضح): Rhizobium leguminosarum bv. trifoli (strain E11) and Anabaena sp. (strain ERC102).

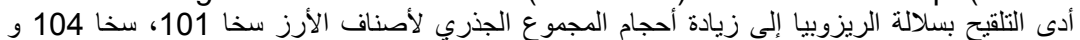

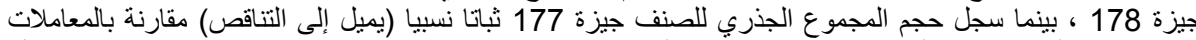

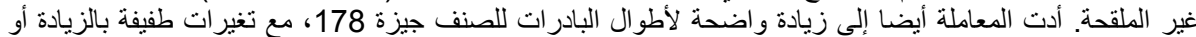

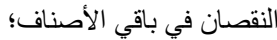

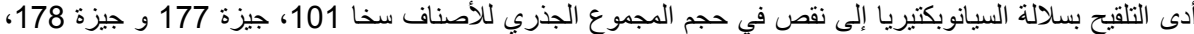

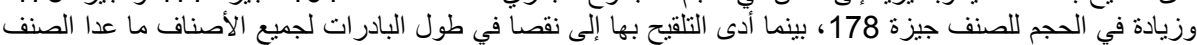

أدى التلقيح بالسلالتين معا إلى زيادة حجم المجموع الجذري للأصناف ما عدا الصنف جيزة 177 الذي سجل جيزة 178؛

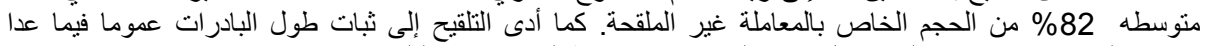

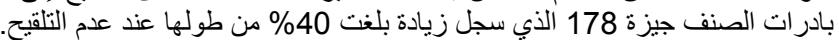

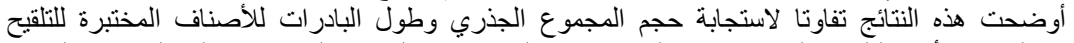

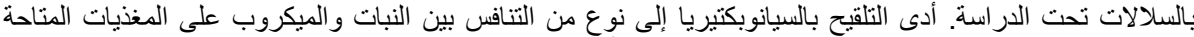

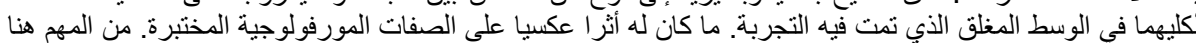

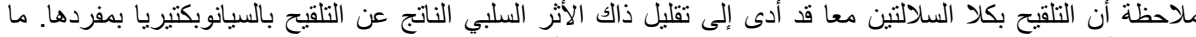

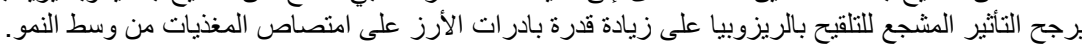

كلية الزراعة - جامعة المنصورة

قام بتحكيم البحث كلية الزراعة - جامعة بنها جاعها

أ.د / أدبد الله العوضى سليم

أ.د / حامد السيد أبو على لئ 